\title{
The Future Looks Bright: Introducing the 2017 TMS
}

\section{Young Leaders}

\section{Ashley-Anne Bohnert}

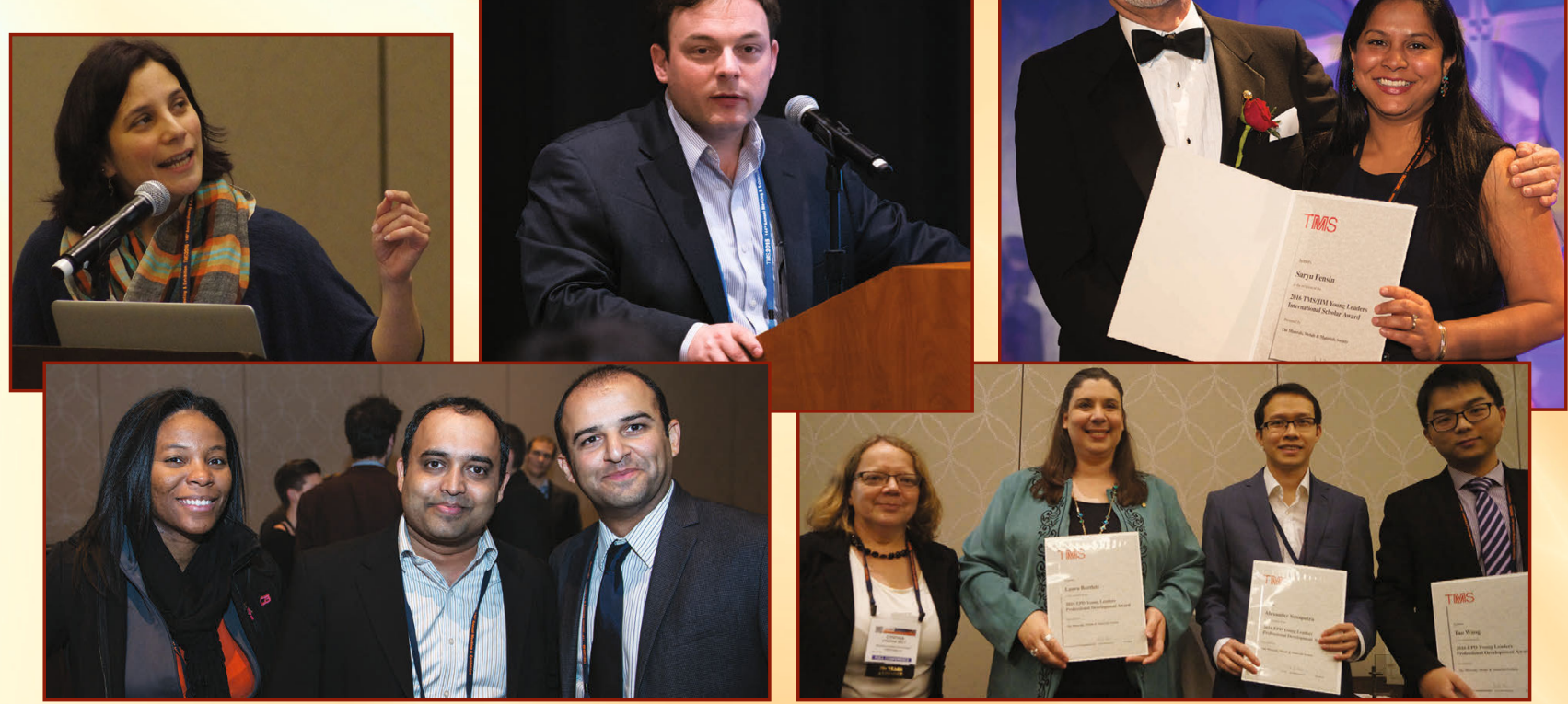

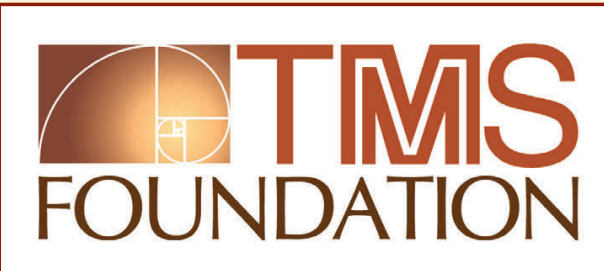

\section{Help Shape the Future of Your Profession with the TMS Foundation}

The opportunities outlined by the many young professionals in this article would not be available without the TMS Foundation and its commitment to developing the next generation of minerals, metals, and materials scientists and engineers. Since its inception, the TMS Foundation has supported more than 260 awards for young professionals and created countless opportunities for networking, mentorship, and professional development. Visit www.TMSFoundation.org to learn more about the TMS Foundation and to help continue its important work through an online donation. For questions or to make a donation by phone or mail, contact Mary Samsa, TMS Foundation \& Public Affairs Manager, at msamsa @tms.org.
At their core, the TMS Young Leaders Professional Development Awards are about giving promising early career professionals the tools to ensure continued growth as members of the minerals, metals and materials community. Awardees receive financial assistance to attend a TMS annual meeting where they have access to a variety of leadership development opportunities, such as attending division council meetings, networking events, and a TMS Board of Directors meeting. Through these and other experiences, TMS Young Leaders gain a valuable perspective on the Society's many voluntary leadership roles while also networking with prominent TMS members.

The 2017 TMS Young Leaders introduced on the following pages will formally accept their awards at the TMS 2017 Annual Meeting \& Exhibition in San Diego, February 26-March 2. If you don't have a chance to congratulate them in person, be sure to add them to your personal network as accomplished members of your professional community. 


\section{Young Leaders Professional Development Award Recipients}

\section{EXTRACTION \& PROCESSING DIVISION (EPD)}

\section{Yousef Mohassab}

Yousef Mohassab is currently a research engineer and research and development project manager at the University of Utah. "Being surrounded by the largest group of dedicated professionals offers more than just a membership," said Mohassab of his experiences with TMS. "I have had the great honor of serving my community as a reviewer for multiple TMS journals and it has kept me up to date with the frontiers in my field. Additionally, my leadership skills grew drastically from interacting with great leaders in the community." Mohassab received both his M.S. and $\mathrm{Ph} . \mathrm{D}$. in metallurgical engineering from the University of Utah, and earned his undergraduate degree in chemistry from Cairo University, Beni-Suef, Egypt.

\section{Huayi Yin}

Huyai Yin is a postdoctoral associate at the Massachusetts Institute of Technology (MIT) where he is currently developing a new ionic selected membrane for liquid displacement batteries. "The TMS Annual Meeting \& Exhibition is the best known meeting in my research field, providing me with a great platform to share my research progress, learn from or communicate with colleagues, and generate new ideas," noted Yin. "Being selected as a TMS Young Leader will further benefit my future career." Yin has more than nine years of expertise in high-temperature molten salts and is an author of 25 peer reviewed papers in this field. He received his Ph.D. in materials and environmental electrochemistry from Wuhan University, China.

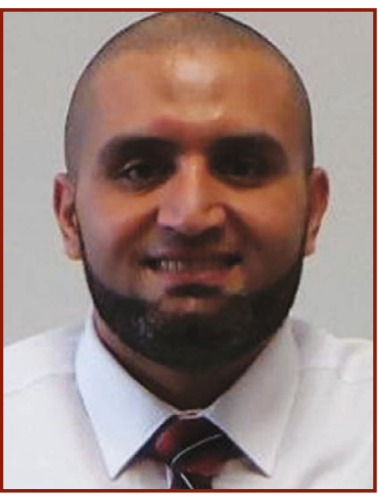

Yousef Mohassab

"The TMS Annual Meeting \& Exhibition is the best known meeting in my research field, providing me with a great platform to share my research progress, learn from or communicate with colleagues, and generate new ideas."

$$
\text { - Huayi Yin }
$$

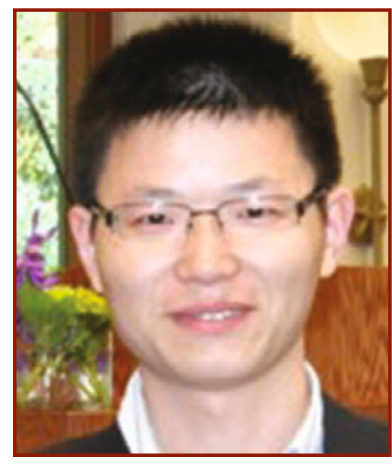

Huayi Yin

\section{FUNCTIONAL MATERIALS DIVISION (FMD)}

\section{Fadi Abdeljawad}

"TMS has always been a professional home for all my research needs," said Fadi Abdeljawad, a senior member of the technical staff in the Computational Materials and Data Science Department at Sandia National Laboratories. "I have benefited tremendously from my TMS membership. The annual meetings have helped me to grow professionally and establish connections with top researchers in the field through formal presentations of my research work, participation in TMS technical committees, organization of symposia, and involvement in young professional activities and poster sessions. I am grateful to the TMS Foundation for funding the Young Leaders Professional Development Award, which will enable me to get more involved in TMS committees and activities."
Abdeljawad received both his M.A. and Ph.D. in mechanical and aerospace engineering from Princeton University. His research interests are aimed at investigating materials microstructures and their evolution in response to a wide range of stimuli, such as thermal, mechanical and/or compositional.

"I am grateful to the TMS

Foundation for funding the Young Leaders Professional

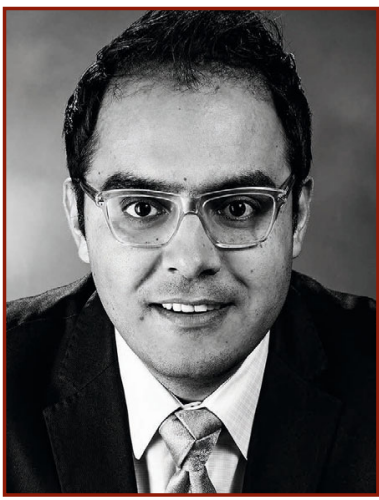

Fadi Abdeljawad

Development Award, which will enable me to get more involved in TMS committees and activities." 


\section{LIGHT METALS DIVISION (LMD)}

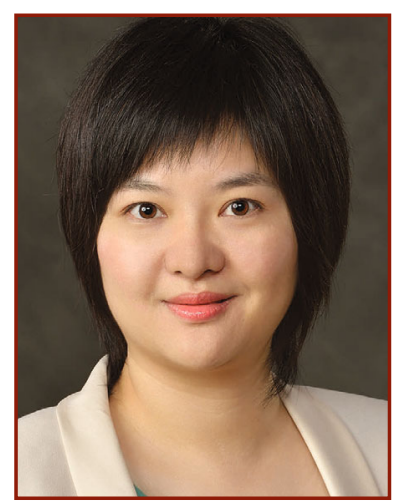

Wenjun Cai

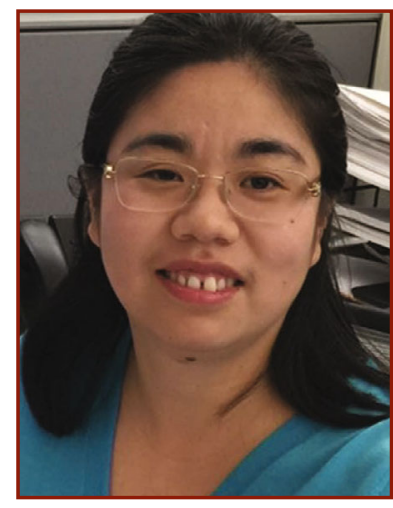

Yi Eva Wang

\section{Wenjun Cai}

"TMS membership has greatly benefited me in different ways throughout my career," said Wenjun Cai, an assistant professor of mechanical engineering at the University of South Florida (USF). "I attended my first TMS meeting when I was a graduate student. There, I received constructive feedback on my research and learned about the exciting new research being done by others. Later on, as a postdoc and assistant professor, TMS and other TMS-sponsored meetings offered great opportunities to share my research, network with other researchers from all over the world, meet old friends, and make new friends."

Cai's current research areas include developing new processing strategies for energy efficient metals and structures, understanding the processing-structureproperty relationship of multilayered and graded lightweight metals, and investigating the tribological and tribocorrosion properties of metals under extreme conditions. She has received the Racheff-Intel award for outstanding graduate research, a National Science Foundation CAREER award, and a USF Outstanding Faculty Award .

\section{Yi Eva Wang}

Yi Eva Wang is a materials scientist at Novelis Inc. and specializes in improving the mechanical properties of various aluminum alloys used in automotive and packing industries by manipulating the microstructure and crystallographic texture through different thermal-mechanical processing development. "TMS provides a unique platform for members to discuss the research frontiers in materials science among a varied group of both academic and industry researchers," commented Wang. "This has helped me in developing my own professional career." Wang earned her Ph.D. in materials science and engineering from the University of Tennessee, and received her master's and undergraduate degrees from Shanghai Jiao Tong University, China.

"TMS provides a unique platform for members to discuss the research frontiers in materials science among a varied group of both academic and industry researchers" - Yi Eva Wang

\section{MATERIALS PROCESSING \& MANUFACTURING DIVISION (MPMD)}

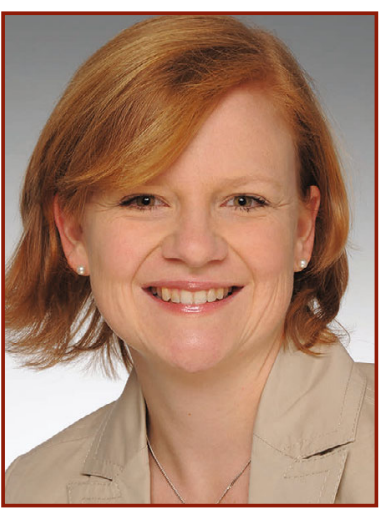

Verena Maier-Kiener

\section{Verena Maier-Kiener}

Verena Maier-Kiener is a group leader for mechanical properties and high performance materials at the Department Physical Metallurgy and Materials Testing at the Montanuniversität Leoben, Austria. Maier-Kiener notes, "To me, TMS is the most important international society in materials sciences, and participation in its activities gives me the chance to interact and collaborate with researchers worldwide. Especially for young researchers, TMS and the TMS Foundation offer an auspicious platform not only to get in touch with established and well known researchers in their field, but to experience first-hand the responsibilities regarding networking activities and symposia organization. Moreover, the broad scientific character of the TMS annual meetings provides an opportunity to meet with researchers from other fields in materials science, which opens new, exciting opportunities for international research projects and collaboration ideas." Maier-Kiener

"Especially for young researchers, TMS and the TMS Foundation offer an auspicious platform not only to get in touch with established and well known researchers in their field, but to experience first-hand the responsibilities regarding networking activities and symposia organization."

- Verena Maier Kiener 
received her diploma and Ph.D. in materials science from the FriedrichAlexander Universität Erlangen-Nürnberg, Germany and received the 2011 Young Researcher Award from the German Society for Materials Science (DGM).

\section{Siddhartha Pathak}

"TMS membership is an important part of my professional career development in the field of materials science," said Siddhartha Pathak, assistant professor, University of Nevada, Reno. "This award and my TMS membership will enable me to enhance my professional development by participating in society activities and establishing contacts with TMS leaders and others in my professional field." Pathak received his $\mathrm{Ph} . \mathrm{D}$. in nanomechanics from Drexel University, where he received the 2009 Drexel University Research Award. His research interests are in the field of nanomechanics, particularly in understanding the mechanical behavior of interfaces in nanostructured materials. Pathak has also co-authored more than 30 peer reviewed articles and two book chapters.

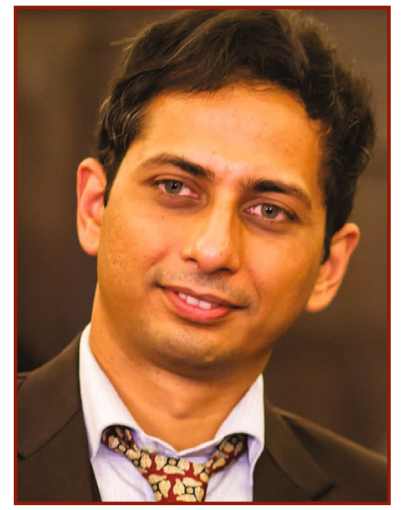

Siddhartha Pathak

\section{STRUCTURAL MATERIALS DIVISION (SMD)}

\section{Joshua Kacher}

Joshua Kacher is an assistant professor of materials science and engineering at Georgia Institute of Technology. Kacher commented, "TMS has provided me with tremendous opportunities over the years to network with leaders in my field and gain insight from high-quality presentations. As an undergraduate researcher, TMS provided some of my initial exposure to materials science research. I now look forward every year to the TMS Annual Meeting \& Exhibition as an opportunity to renew contact with my colleagues and establish new collaborations going forward. I am excited and humbled at the increased opportunity to participate in TMS, as a result of this Young Leaders Professional Development Award." His primary research interests are in understanding the mechanical and chemical behavior of materials in extreme environments using in situ electron microscopy techniques. Kacher received his Ph.D. from the University of Illinois at UrbanaChampaign.

"TMS has provided me with tremendous opportunities over the years to network with leaders in my field and gain insight from highquality presentations."

- Joshua Kacher

\section{Robert Maass}

"I am very grateful for this recognition that comes directly from the heart of my community," said Robert Maass, assistant professor of materials science and engineering at the University of Illinois at Urbana-Champaign. "As a student at TMS meetings, I had the opportunity to share research or meet the leading core of my research community. I am always impressed and stimulated by the innovative and dynamic atmosphere at the TMS Annual Meeting \& Exhibition and am looking forward to introducing my students to the nurturing atmosphere the TMS Foundation provides." Maass obtained his Ph.D. from the École Polytechnique Fédérale de Lausanne (EPFL) in Switzerland. His research interests include microstructure-property relations, size effects, strain localization and defect structures of amorphous and crystalline metals, defect dynamics, mechanical properties, microplasticity, glass transition phenomena, and test system development.

"I am always impressed and

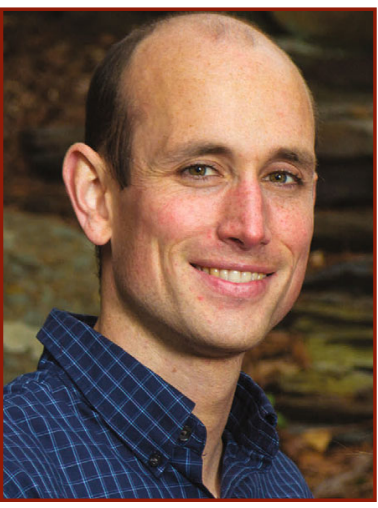

Joshua Kacher

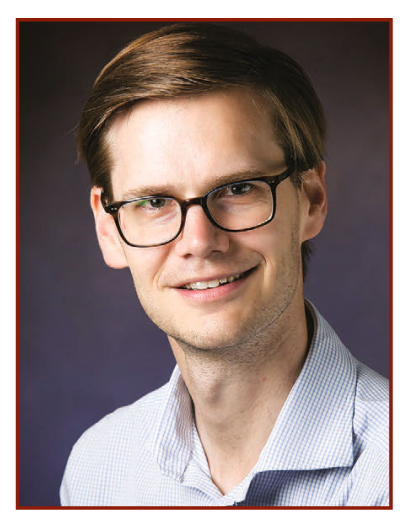

Robert Maass

stimulated by the innovative and dynamic atmosphere at the TMS Annual Meeting \& Exhibition and am looking forward to introducing my students to the nurturing atmosphere the TMS Foundation provides." 


\section{TMS Young Leaders International Scholar Awards}

The TMS Young Leaders

International Scholar program was established in 2006 as a collaboration between TMS and the Japan Institute of Metals (JIM) and expanded in 2013 to include a second award conferred as a collaboration between TMS and the Federation of European Materials Societies (FEMS). Made possible by funding from the TMS Foundation, the TMS Young Leaders International Scholar Awards enable early career TMS members to travel to the JIM or FEMS annual meetings where they present a paper and tour nearby universities, research labs or industrial facilities.

This year's recipient of the TMS/JIM Young Leaders International Scholar Award is Kinga Unocic, a research staff scientist at Oak Ridge National Laboratory. "It is a great honor to be chosen for this award which will allow me to present my research at the JIM annual meeting," said Unocic. "The TMS Foundation has played, and will continue to play, a major role in my professional career by allowing me to engage with and hold leadership roles in TMS professional development and diversity initiatives, as well as scientific committees. I have also been fortunate to organize several symposia on high temperature alloys, corrosion, and additive manufacturing programs at the Materials Science \& Technology and TMS annual meetings. TMS's commitment to its societal involvement allows young researchers to be a part of a global initiative to advance science that will have a great technological and societal impact for many generations to come."

Unocic received her undergraduate degree in metallurgical engineering from AGH University of Science and Technology in Poland, and an M.S. and a Ph.D. in materials science and engineering from The Ohio State University. Unocic is also a recipient of the 2010 TMS Young Leaders Professional Development Award.
Mohsen Asle Zaeem, the 2017 TMS/FEMS Young Leaders International Scholar, is an assistant professor of materials science and engineering at Missouri University of Science and Technology. His current research focuses on investigating and predicting the mechanisms controlling the structure-propertyprocessing relations in materials by utilizing multiscale computational simulations. His interests also extend to solidification, grain formation, recrystallization, solid state phase transformation, and deformation mechanisms of lightweight and functional materials.

As a TMS member, he has served on numerous committees and been actively involved in past annual meetings as an organizer, co-organizer and session chair. Zaeem has also served as a JOM guest editor and is the current vice chair of the TMS Young Professionals Committee.

In speaking on the opportunities afforded by the International Scholar Award, Zaeem stated, "I believe that it will provide an excellent opportunity for me to network with international professionals, expand my leadership skills in representing TMS young professionals and TMS technical committees to international researchers and engineers, and also create a foundation for international research collaborations."

Zaeem received his B.Sc. and M.Sc in Mechanical Engineering from Shiraz University in Iran and his Ph.D. in Mechanical engineering from Washington State Univeristy.

"The TMS Foundation has played, and will continue to play, a major role in my professional career by allowing me to engage with and hold leadership roles in TMS professional development and diversity initiatives, as well as scientific committees." -Kinga Unocic 


\section{Early Career Faculty Fellow Award}

The Early Career Faculty Fellow Award, funded by the TMS Foundation, honors two assistant professors each year for accomplishments that have advanced the academic institution at which they are employed. The award also acknowledges the recipients' potential to broaden the technological profile of TMS. Honorees present talks at the Young Leader Tutorial Luncheon during the TMS annual meeting in the year that they receive the award. The following year, they must play an organizing role in one of the TMS annual meeting symposia.

"I've been going to TMS meetings for more than 10 years and they have always provided me with a much needed reality check, connecting societal and industrial needs with academic research," notes Kristin Persson, one of the 2017 TMS Early Career Faculty Fellows. "The topics and symposia at the TMS Annual Meeting \& Exhibition reflect a clear assessment of the current state of affairs, which opens up an honest dialogue between scientists in the community. I am incredibly honored by the award and look forward to further contributing to TMS and its community." Persson is currently a staff scientist at Lawrence Berkeley National Laboratory. She studies the physics and chemistry of materials using atomistic and first-principles computational methods coupled with high-performance computing technology, particularly for clean energy production and storage applications.
Guihua Yu, an assistant professor at the University of Texas and the second 2017 Early Career Faculty Fellow, said, "I am truly honored to receive this prestigious award supported by the TMS Foundation. TMS and its society meetings provide a large array of career and technical development programs that benefit young researchers working in materials science and engineering. These have helped me grow professionally and connect with fellow scientists and engineers in both industry and academia. I am very excited to be part of the growth and advancement of TMS and the TMS Foundation, and I truly look forward to contributing to future TMS activities and the TMS community." Yu received his B.S. degree from the University of Science and Technology of China, and earned his Ph.D. from Harvard University, followed by postdoctoral training at Stanford University. His research examines the intersection of materials science, chemical science, and energy science and technology. A particular focus of his work is advancing chemical synthesis, fundamental understanding, and technological applications of novel nanostructured organic and hybrid organic-inorganic materials for energy, environment, and healthcare technologies.

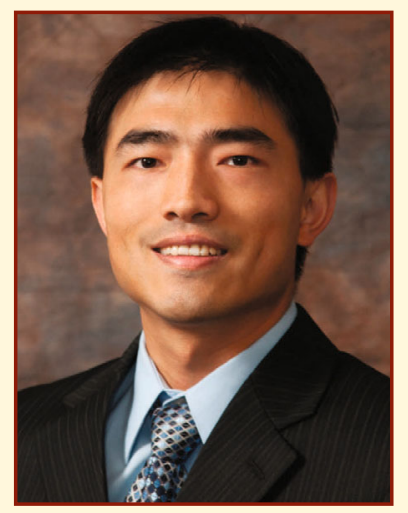

Guihua Yu
"I've been going to TMS meetings for more 10 years and they have always provided me with a much needed reality check, connecting societal and industrial needs with academic research." -Kristin Persson

\section{Do You Know a Future TMS Young Leader?}

Those receiving TMS Young Leaders Professional Development Awards are dynamic and driven individuals with a desire to enhance their leadership skills. They recognize the value of TMS's strategic initiatives and wish to make a meaningful impact on the minerals, metals, and materials community by serving as TMS volunteers.

If this describes you or someone you know, visit the TMS Honors and Awards website at awards.tms.org to learn more and download an application form. All applicants must be TMS members in good standing and under the age of 40 . Awardees must also demonstrate a desire to play an active role in TMS and the potential to advance to volunteer leadership roles within the society.

The deadline for all 2018 Young Leaders Awards is August 15, 2017.

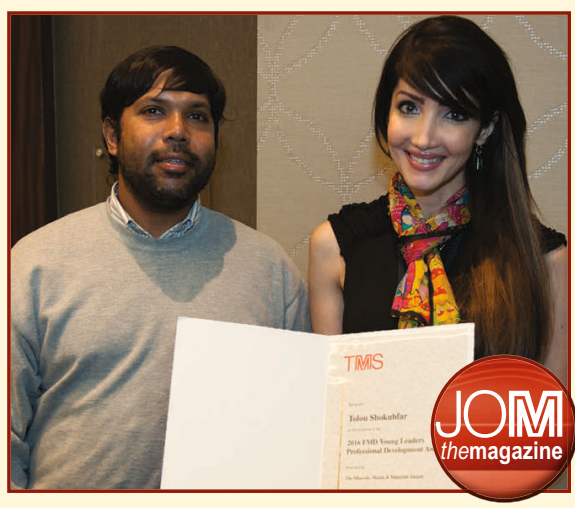

